\title{
Microstructure, Tensile Properties and Work Hardening Behavior of an Extruded Mg-Zn-Ca-Mn Magnesium Alloy
}

\author{
Kai-Bo Nie ${ }^{1}$ Zhi-Hao Zhu ${ }^{1} \cdot$ Paul Munroe ${ }^{2} \cdot$ Kun-Kun Deng ${ }^{1} \cdot$ Jun-Gang Han ${ }^{1}$ \\ Received: 30 January 2020 / Revised: 26 March 2020 / Published online: 12 May 2020 \\ (c) The Chinese Society for Metals (CSM) and Springer-Verlag GmbH Germany, part of Springer Nature 2020
}

\begin{abstract}
A new Mg-2.2 wt \% Zn alloy containing $1.8 \mathrm{wt} \% \mathrm{Ca}$ and $0.5 \mathrm{wt} \% \mathrm{Mn}$ has been developed and subjected to extrusion under different extrusion parameters. The finest $(\sim 0.48 \mu \mathrm{m})$ recrystallized grain structures, containing both nano-sized $\mathrm{MgZn}_{2}$ precipitates and $\alpha$-Mn nanoparticles, were obtained in the alloy extruded at $270{ }^{\circ} \mathrm{C} / 0.01 \mathrm{~mm} \mathrm{~s}^{-1}$. In this alloy, the deformed coarse-grain region possessed a much stronger texture intensity ( $\sim 32.49$ mud) relative to the recrystallized fine-grain region $(\sim 13.99$ mud). A positive work hardening rate in the third stage of work hardening curve was also evident in the alloy extruded at $270{ }^{\circ} \mathrm{C}$, which was related to the sharp basal texture and which provided insufficient active slip systems. The high work hardening rate in the fourth stage contributed to the high ductility extruded at $270{ }^{\circ} \mathrm{C} / 1 \mathrm{~mm} \mathrm{~s}^{-1}$. This alloy exhibited a weak texture, and the examination of fracture surface revealed highly dimpled surfaces. The optimum tensile strength was achieved in the alloy extruded at $270{ }^{\circ} \mathrm{C} / 0.01 \mathrm{~mm} \mathrm{~s}^{-1}$, and the yield strength, ultimate tensile strength and elongation to failure were $364.1 \mathrm{MPa}, \sim 394.5 \mathrm{MPa}$ and $7.2 \%$, respectively. Fine grain strengthening from the recrystallized fine-grain region played the greatest role in the strength increment of this alloy compared with Orowan strengthening and dislocation strengthening in the deformed coarse-grain regions.
\end{abstract}

Keywords Magnesium alloy $\cdot$ Mixed grain structure $\cdot$ Mechanical properties $\cdot$ Work hardening behavior

\section{Introduction}

$\mathrm{Mg}-\mathrm{Zn}$ series alloys have received widespread attention owing to their low cost, high creep resistance and biocompatibility [1-3]. However, these alloys exhibit some limitations, such as poor formability and poor mechanical properties at room temperature. These properties for $\mathrm{Mg}-\mathrm{Zn}$ alloys have been ascribed to the lack of slip systems originating from the hexagonal close packed structure [4]. Recently, it has been shown that $\mathrm{Mg}-\mathrm{Zn}$ micro-alloyed with $\mathrm{Ca}$ can significantly refine the grain size, decrease basal texture

Available online at http://link.springer.com/journal/40195.

Kai-Bo Nie

kaibo.nie@gmail.com

Paul Munroe

p.munroe@unsw.edu.au

1 College of Materials Science and Engineering, Taiyuan University of Technology, Taiyuan 030024, China

2 School of Materials Science and Engineering, UNSW Australia, Kensington, NSW 2052, Australia intensity and boost formability [5]. Kang et al. [6] reported that a low Ca concentration (e.g., $0-0.5 \mathrm{wt} \%$ ) led to the inhibition of the growth of recrystallized grains in a $\mathrm{Mg}-\mathrm{Zn}$ alloy. Furthermore, the grain size of magnesium alloys also decreased by alloying additions such as $\mathrm{Zr}$ [7] or $\mathrm{Mn}$ [8]. For instance, the grain size of as-extruded $\mathrm{Mg}-5.25 \mathrm{Zn}-0.6 \mathrm{Ca}$ (wt\%) was significantly refined by adding $0.3 \mathrm{wt} \% \mathrm{Mn}$ [9].

There has been much attention given to magnesium alloys containing high concentrations of $\mathrm{Zn}$ (usually between 3 and $6 \mathrm{wt} \%$ ) [10-12] and low concentrations of $\mathrm{Ca}$ (usually between 0.2 and $1 \mathrm{wt} \%$ ) [13-18]. Du et al. [10] found that the tensile strength of an as-extruded $\mathrm{Mg}-6 \mathrm{wt} \% \mathrm{Zn}$ alloy could be effectively improved by $\mathrm{Ca}(0.36-0.82 \mathrm{wt} \%)$ addition. Xu et al. [11] reported that during indirect extrusion process, fine-grained structures were preferentially formed in the untwinned matrix and near the intermetallic compounds in $\mathrm{Mg}-5.99 \mathrm{Zn}-1.76 \mathrm{Ca}-0.35 \mathrm{Mn}$ (wt\%) alloy. Shuai et al. [12] investigated the anisotropy of the solid-liquid interfacial energy for $\mathrm{Mg}-\mathrm{Zn}$ alloys, which increased with increasing the $\mathrm{Zn}$ concentration to $50 \mathrm{wt} \%$. Oh-ishi et al. [13] obtained the highest peak hardness of a $\mathrm{Mg}-0.3 \mathrm{Ca}-\mathrm{Zn}$ alloy as $\mathrm{Zn}$ additions up to 0.6 (at\%). Further, the second 
$\mathrm{Ca}_{2} \mathrm{Mg}_{6} \mathrm{Zn}_{3}$ phases distributed at the grain boundaries of ascast $\mathrm{Mg}-4.50 \mathrm{Zn}-1.13 \mathrm{Ca}$ (wt\%) alloy led to poor mechanical properties and can be improved after extrusion [14]. Jiang et al. [15] found that $\mathrm{Mg}-0.21 \mathrm{Zn}-0.30 \mathrm{Ca}-0.14 \mathrm{Mn}$ (wt\%) alloys extruded at die-exit speed over $6 \mathrm{~m} / \mathrm{min}$ showed a fully dynamically recrystallized microstructure and weak rare earth (RE) texture. Zhang et al. [16] investigated the effects of calcium on texture and mechanical properties of hot-extruded $\mathrm{Mg}-1 \mathrm{Zn}-\mathrm{Ca}$ (wt\%) alloys and found that the increase in $\mathrm{Ca}$ concentration could weaken extrusion textures and refine grains, resulting in tensile elongation improvement. Kang et al. [17] reported that there is a high dynamic recovery rate at the third stage of the $\mathrm{Mg}-4 \mathrm{Zn}-0.5 \mathrm{Ca}$ (wt\%) alloy, which can be attributed to the large amount of fine recrystallized grains after the combination of forging, homogenization and extrusion process. Hofstetter et al. [18] developed a Mg-1Zn-0.3Ca (wt\%) alloy which exhibited yield strength of $\sim 265 \mathrm{MPa}$ and elongation to failure of $\sim 30 \%$ after indirect extrusion at $300{ }^{\circ} \mathrm{C}$. However, the previous $\mathrm{Mg}-\mathrm{Zn}-\mathrm{Ca}$ series alloys typically exhibited an ultimate tensile strength less than $380 \mathrm{MPa}$ as well as poor ductility. The increase in the concentration of alloying elements can significantly enhance the tensile strength of the Mg alloys, but inevitably push up material cost. Further, the formation of coarse second phases which can act as crack initiators would be promoted by adding high alloying concentrations, so reducing the ductility of as-cast magnesium alloys $[19,20]$. Therefore, in the current work, a new $\mathrm{Mg}-2.2 \mathrm{wt} \% \mathrm{Zn}$ alloy containing $1.8 \mathrm{wt} \% \mathrm{Ca}$ and $0.5 \mathrm{wt} \% \mathrm{Mn}$ has been developed as one means to overcome these limitations.

Extrusion as an industrially economic and effective deformation technology has been widely used to further optimize the strength of $\mathrm{Mg}$ alloys. $\mathrm{Li}$ et al. [21] reported that the grain size of a $\mathrm{Mg}-3.0 \mathrm{Zn}-0.2 \mathrm{Ca}$ (wt\%) alloy monotonically increased as extrusion temperature increased from 25 to $300{ }^{\circ} \mathrm{C}$, and an excellent elongation of $36.7 \%$ was obtained when the alloy was extruded at $300{ }^{\circ} \mathrm{C}$. The influence of extrusion parameters such as temperatures $\left(190-400^{\circ} \mathrm{C}\right)[3$, 20] and extrusion speeds $\left(5-0.01 \mathrm{~mm} \mathrm{~s}^{-1}\right.$ ) on Mg-RE-based alloys [19] has also been investigated in previous studies. However, the literature suggests that there is little work regarding the relationship between extrusion conditions and microstructure, texture, mechanical properties as well as strain hardening behavior of low-alloyed $\mathrm{Mg}-\mathrm{Zn}$-based compositions, especially with a high $2.2 \mathrm{wt} \%$ Ca concentration and dilute $0.5 \mathrm{wt} \% \mathrm{Mn}$ concentration.

Therefore, in the present study a Mg-2.2 wt\% $\mathrm{Zn}$ alloy containing $1.8 \mathrm{wt} \% \mathrm{Ca}$ and $0.5 \mathrm{wt} \% \mathrm{Mn}$ was prepared and extruded at different extrusion parameters. The effect of extrusion speeds and extrusion temperatures on the microstructure, tensile strength and work hardening behavior of this alloy was investigated.

\section{Experimental}

\subsection{Preparation and Extrusion of the Alloy}

The pure magnesium (99.98\%), Zn (99.99\%), Mg-15Mn (wt\%) and $\mathrm{Mg}-20 \mathrm{Ca}$ (wt\%) master alloys were used to prepare the $\mathrm{Mg}-2.2 \mathrm{Zn}-1.8 \mathrm{Ca}-0.5 \mathrm{Mn}$ (wt \%) alloy, which was denoted as ZXM alloy. The melting process of ZXM alloy was completed in an electric resistance furnace, and the mixture of $\mathrm{CO}_{2}-\mathrm{SF}_{6}$ was used as shielding gas. Finally, the alloy melt was solidified in a steel mold which was preheated to $250{ }^{\circ} \mathrm{C}$. Before extrusion, the ingots were firstly subjected to homogenized. The two-step homogenization treatment was applied according to Ref. [5]. The homogenization process was as follows: Firstly, the ingot was kept at $320{ }^{\circ} \mathrm{C}$ for $8 \mathrm{~h}$, and then reheated to $430{ }^{\circ} \mathrm{C}$ and held for $16 \mathrm{~h}$, subsequently quenched in water. The first process at $320{ }^{\circ} \mathrm{C}$ for $8 \mathrm{~h}$ was to prevent the remelting of grain boundaries leading to the deterioration of the strength. During the second process at $430{ }^{\circ} \mathrm{C}$ for $16 \mathrm{~h}$, the eutectic $\mathrm{Ca}_{2} \mathrm{Mg}_{6} \mathrm{Zn}_{3}$ phases can be almost dissolved. After the homogenization treatment, each billet $(\phi 40 \mathrm{~mm} \times 50 \mathrm{~mm})$ was heated to the set temperature $\left(270-350{ }^{\circ} \mathrm{C}\right)$ using a resistance furnace and held for $0.5 \mathrm{~h}$ before extrusion. The direct extrusion conditions were set as follows: with a constant extrusion ratio of $16: 1$, extrusion temperatures of 270 and $350{ }^{\circ} \mathrm{C}$ at a constant extrusion speed of $0.01 \mathrm{~mm} / \mathrm{s}$, or extrusion speeds of 0.01 and $1 \mathrm{~mm} / \mathrm{s}$ under an extrusion temperature of $270{ }^{\circ} \mathrm{C}$. The as-extruded bars were denoted as ZXM-270/0.01, ZXM-270/1, ZXM-350/0.01, respectively.

\subsection{Microstructure Observation}

Microstructure characterization of the ZXM alloy was carried out using a 4XC optical microscope (OM), LMH scanning electron microscope (SEM, TESCAN Ltd., BrnoKohoutovice, Czech Republic) equipped with energydispersive spectrometry (EDS). Phase analysis was carried out by X-ray diffraction (XRD) and transmission electron microscopy (TEM, JEM-2100(HR)). The textures of the specimens were investigated via electron backscattered diffraction (EBSD, Hitachi S-3400 N SEM) equipped with an HKL-EBSD system. Samples for OM, SEM and EBSD analysis were all cut along the extrusion direction (ED). The EBSD samples were prepared by grinding on the different emery papers, then followed by electro-polished with the $5 \%$ perchloric acid solution at $-30{ }^{\circ} \mathrm{C}$ for $1.5 \mathrm{~min}$. The dates from the EBSD were analyzed by using the channel 5 software. After grinding (using emery papers up to \#4000) and polishing, the OM and SEM samples were 
chemically etched in a liquid mixture of oxalic acid solution $(200 \mathrm{~mL}$ distilled water $+8 \mathrm{~g}$ oxalic acid $)$ and a mixture nitric acid and alcohol $(200 \mathrm{~mL}$ alcohol $+7 \mathrm{ml}$ nitric acid) and with a volumetric ratio of 3:2. The fraction of dynamic recrystallization (DRX) was determined using low-magnification OM images, and the average size of dynamic recrystallized (DRXed) grains was measured by higher-magnification OM images. Quantitative analysis of the precipitates was performed on the SEM micrographs, and the average size and volume fraction were measured using Image-Pro Plus 6.0 software. Firstly, each precipitate in SEM image was marked using a Photoshop software, and then, the average precipitate size can be calculated by an IPP software. The corresponding statistical results were put into Origin software, and the volume fraction of precipitates can be also obtained. The volume fraction $\left(V_{\mathrm{DRX}}\right)$ of DRXed grains can be calculated by the following equation [22]: $V_{\mathrm{DRX}}=\frac{S_{\mathrm{DRX}}}{S_{\mathrm{DRX}+S_{\mathrm{unRX}}}}$, where $S_{\mathrm{DRX}}$ stands for the total area of DRXed regions while the $S_{\text {unDRX }}$ represents the remnant unrecrystallized zones, which were measured from at least three images for each condition.
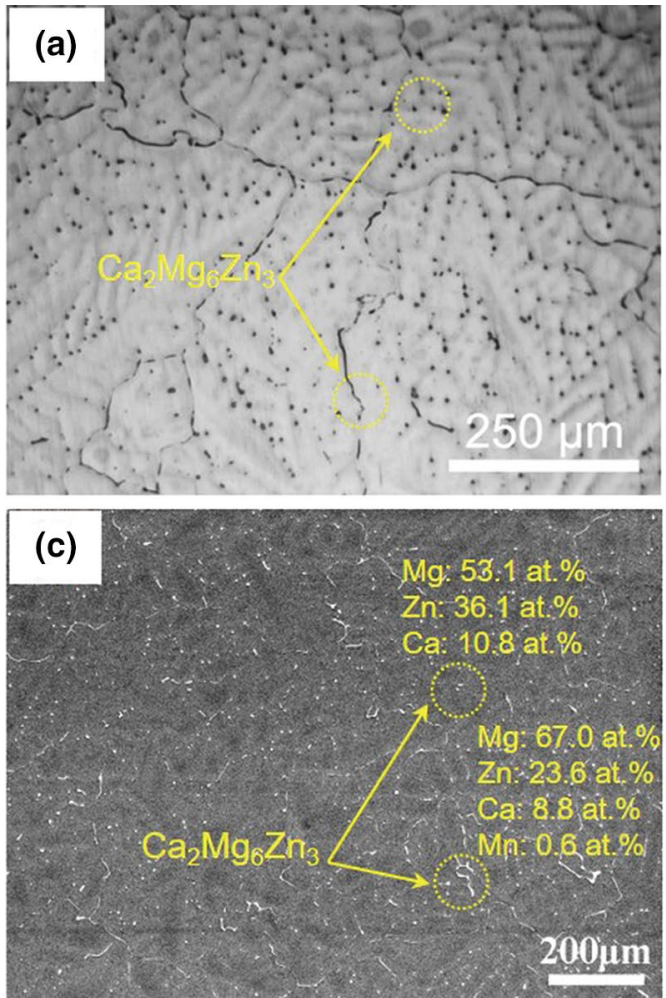

\subsection{Tensile Test}

Plate-shaped specimens along the extrusion direction (ED), with a gage section of $15 \mathrm{~mm}$ and cross-sectional area of $6 \mathrm{~mm} \times 2 \mathrm{~mm}$, were subjected to uniaxial tensile test. Testing was performed at room temperature under a strain rate of $0.5 \mathrm{~mm} / \mathrm{min}$ using an Instron Series 3369 test machine. Three tensile samples were machined from each processing condition.

\section{Results and Discussion}

\subsection{Microstructures of the As-Cast and As-Homogenized Alloy}

Figure 1a-d depicts OM and SEM images of the alloy before and after the homogenization treatment. There exist many coarse dendritic grains with average size of $\sim 293 \mu \mathrm{m}$ in the as-cast alloy (Fig. 1a, c). Many discontinued netlike intermetallic compounds are preferentially aligned along grain boundaries as well as globular-like compounds located within inter-dendritic. An XRD spectrum (in Fig. 2) shows that the as-cast alloy is comprised of $\alpha$ $-\mathrm{Mg}$ and $\mathrm{Ca}_{2} \mathrm{Mg}_{6} \mathrm{Zn}_{3}$ phases. By combining the XRD and EDS results, both the net-like intermetallic and spherical
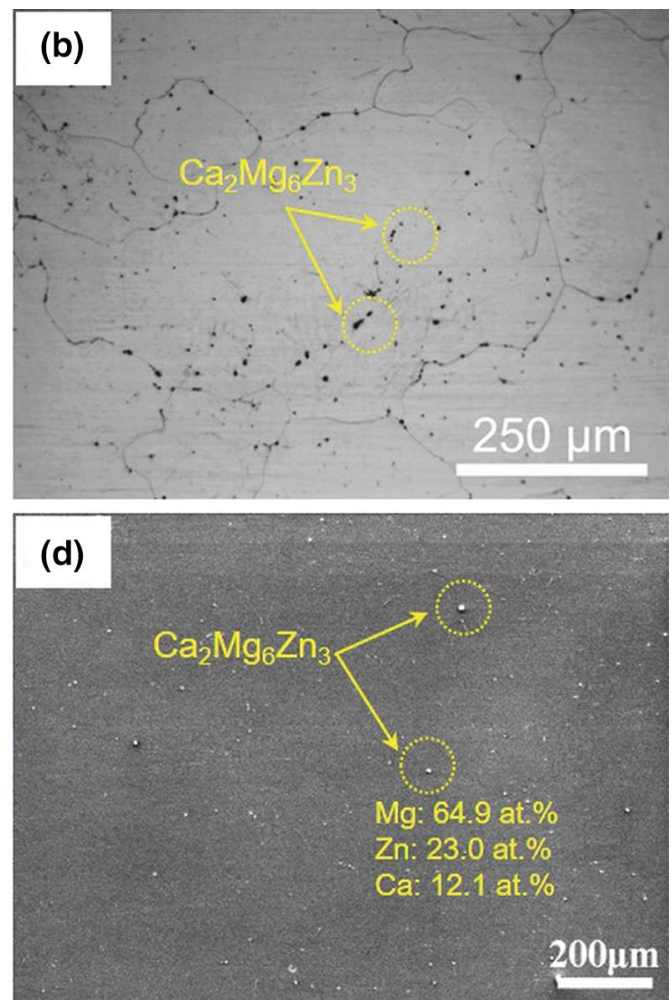

Fig. $1 \mathrm{OM}$ and SEM micrographs of the ZXM alloy: a, $\mathbf{c}$ as-cast, $\mathbf{b}, \mathbf{d}$ homogenization treatment 


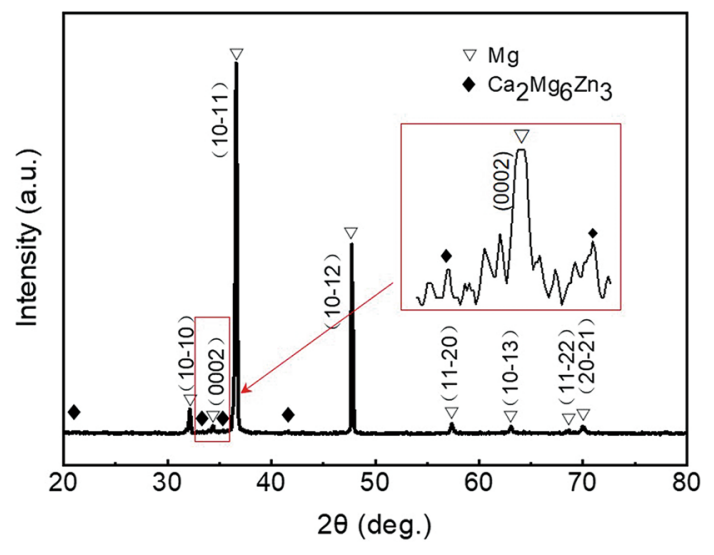

Fig. 2 XRD spectra of as-cast ZXM alloy

compounds in the as-cast billets can be confirmed as $\mathrm{Ca}_{2} \mathrm{Mg}_{6} \mathrm{Zn}_{3}$ phases. The formation of coarse dendrite grains can be related to the anisotropy of the solid/liquid interfacial energy originating from solute atoms and the movement of the solid-liquid zone during non-equilibrium solidification $[12,23]$. After the homogenization treatment, there is clear change in the grain size in the alloys ( $296 \mu \mathrm{m}$, Fig. 1b), while the eutectic phases are almost completely dissolved in the matrix. The remnant $\mathrm{Ca}_{2} \mathrm{Mg}_{6} \mathrm{Zn}_{3}$ particles tend to distribute both inside grains and on grain boundaries (Fig. $1 \mathrm{~b}-\mathrm{d}$ ). $\mathrm{Mg}-\mathrm{Zn}$ phase is not observed in the as-cast alloy because the diffusion rate of $\mathrm{Ca}$ in the matrix is higher than that of $\mathrm{Zn}[5,24]$. In the liquid layer, significant constitutional supercooling caused by the $\mathrm{Ca}$ addition promotes the solidification of primary $\alpha-\mathrm{Mg}$ phase, resulting in enrichment in $\mathrm{Ca}$ and $\mathrm{Zn}$ at the liquid-solid growth interface. Consequently, the eutectic composition forms in the inter-dendritic regions, resulting from the occurrence of the binary eutectic reaction ( $\mathrm{L} \rightarrow \alpha-\mathrm{Mg}+\mathrm{Ca}_{2} \mathrm{Mg}_{6} \mathrm{Zn}_{3}$ [25]). As a result, both net-like and spherical $\mathrm{Ca}_{2} \mathrm{Mg}_{6} \mathrm{Zn}_{3}$ phases and $\alpha-\mathrm{Mg}$ are formed in the as-cast ZXM alloy.
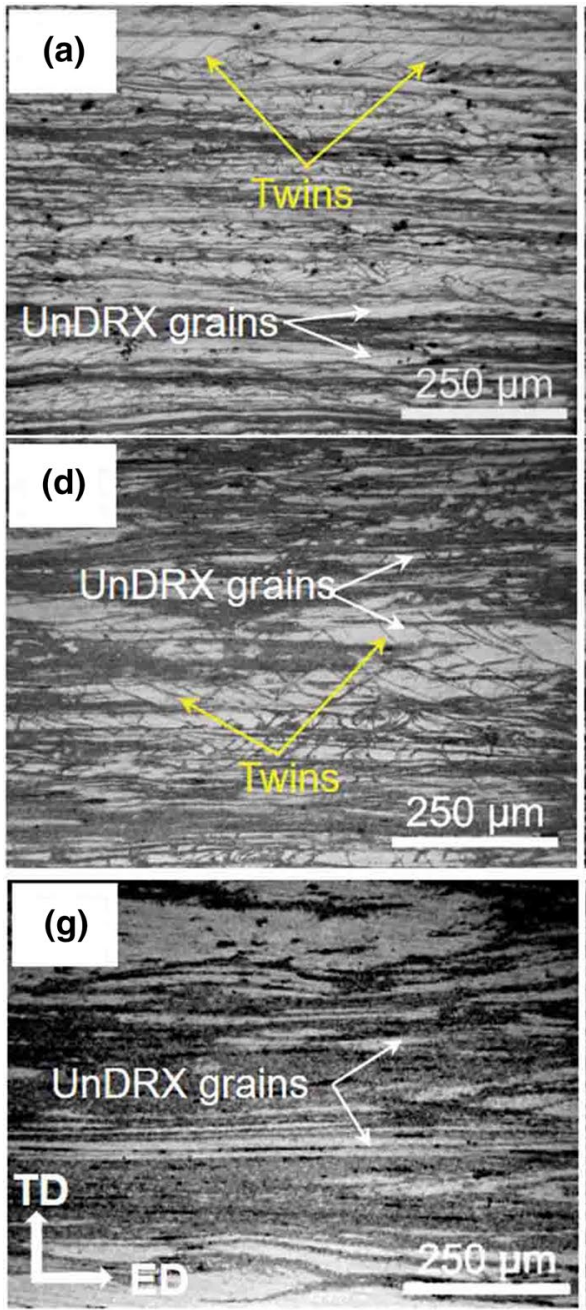
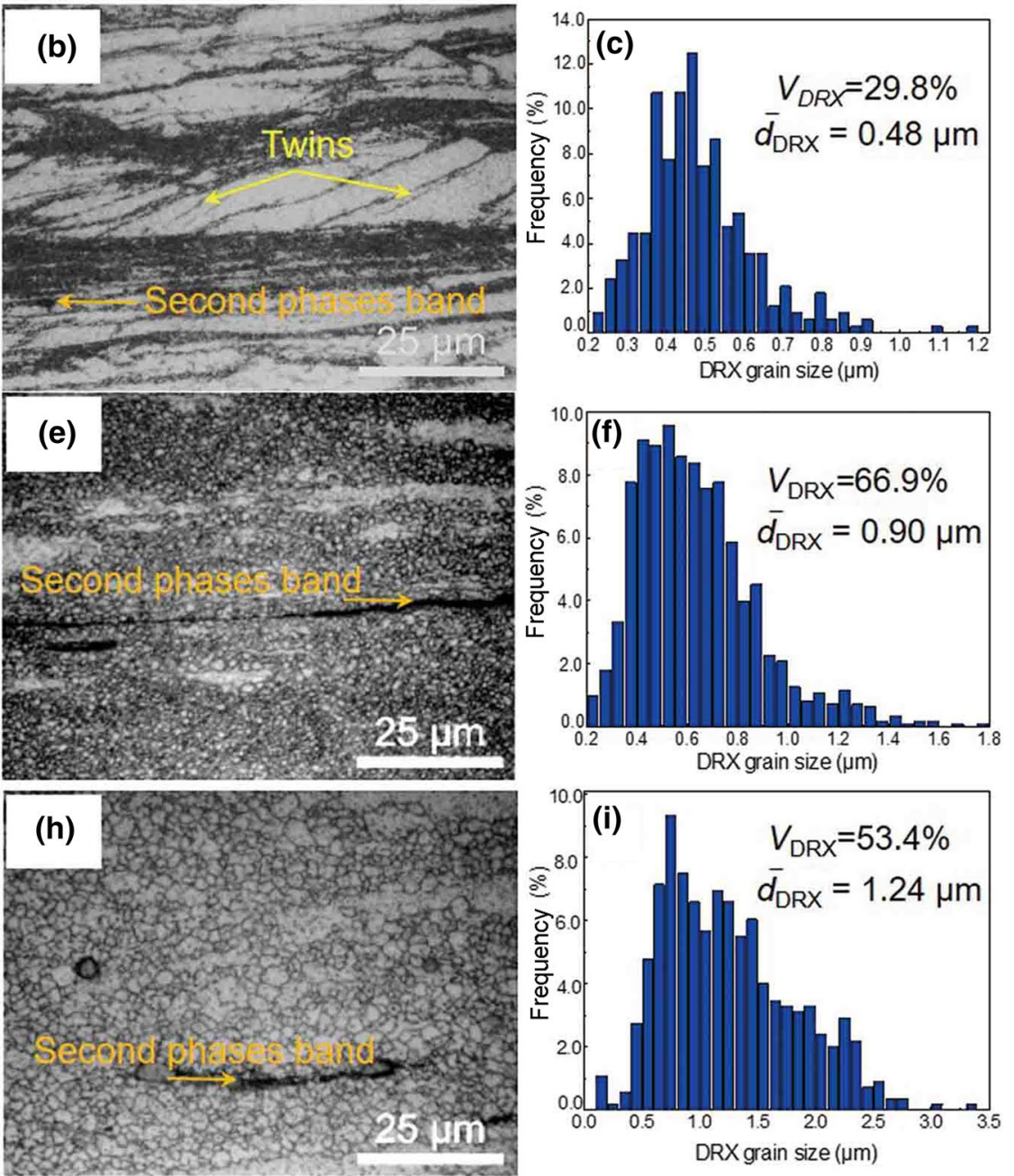

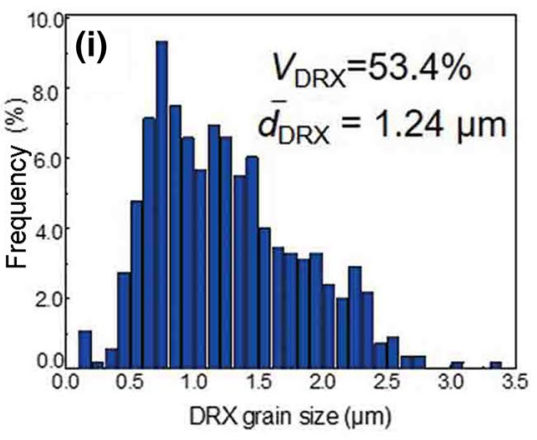

Fig. 3 OM micrographs and corresponding grain size distributions of a-c ZXM-270/0.01, d-f ZXM-270/1, g-i ZXM-350/0.01 


\subsection{Microstructures of the As-Extruded Alloy}

Figure 3a-i depicts the OM images of the as-extruded alloy and corresponding grain size distributions. As depicted in Fig. 3a, d, g, all the as-extruded alloys exhibit a mixed structure consisting of fine grained DRXed regions together with coarser unDRXed regions. As marked by yellow arrows in Fig. 3a, d, a large number of twins can also be observed in the alloys extruded at $270{ }^{\circ} \mathrm{C}$. Limited slip systems can be activated for the magnesium alloy when extruded at lower temperatures [26, 27], which is distinct from the samples extruded at higher temperatures. With the increase in the extrusion temperature, more slip systems become activated, so fewer twins can be found in the ZXM-350/0.01 sample. With the increase in the ram speed or elevating the ram temperature, as shown in Fig. 3b, e, h, the DRXed grain size gradually increases after extrusion. The distribution of DRXed grain size is normal for the ZXM-270/0.01 sample (Fig. 3c), while with increasing extrusion speed (up to $1 \mathrm{~mm} / \mathrm{s}$, in Fig. 3f) or temperature (up to $350{ }^{\circ} \mathrm{C}$, in Fig. 3i), this distribution becomes more asymmetric. There is a rather homogeneous microstructure observed in the ZXM-270/0.01 sample and a mixed microstructure for both the ZXM-270/1 and ZXM-350/0.01 samples. In addition, there is still some residual second phases observed elongated along the extrusion direction (marked by brown arrows, e.g., in Fig. 3a, d, g).

Figure 4a-c depicts secondary electron images and the corresponding EDS composite elemental maps for the ZXM-270/0.01 sample. Some undissolved second phases distributed along the extrusion direction are broken up under pressure after extrusion (Fig. 4a, b). The remnant blocks of intermetallic compounds marked by the red circle in the secondary electron micrographs contain mainly $\mathrm{Zn}$ and $\mathrm{Ca}$ (see Fig. 4c).

Figure $5 \mathrm{a}-\mathrm{f}$ presents secondary electron images of the alloy extruded under different conditions. The increase in the extrusion speed (ZXM-270/1, in Fig. 5c, d) or extrusion temperature (ZXM-350/0.01, in Fig. 5e, f) leads to an increase in the size of the precipitates. These precipitates formed during the hot extrusion process and are confirmed to be $\mathrm{MgZn}_{2}$ based on EDS analysis.

Figure 6 shows bright-field transmission electron microscope images of the ZXM-270/0.01 sample. As mentioned in
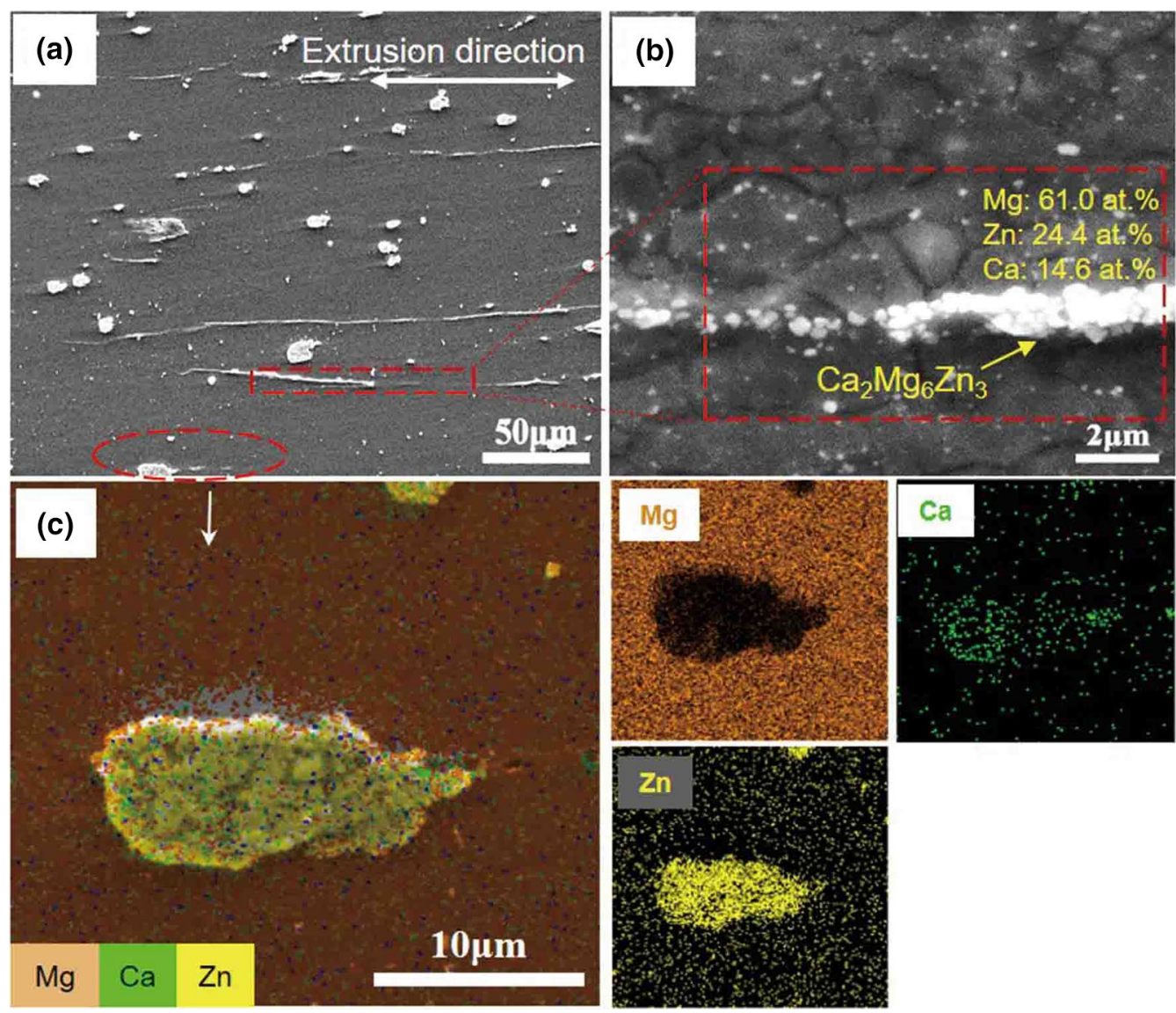

Fig. 4 Secondary electron images and EDS composite maps of the ZXM-270/0.01 sample: a SEM image at low magnification, b SEM image at high magnification, $\mathbf{c}$ EDS composite maps (Mg map, Ca map and Zn map) 

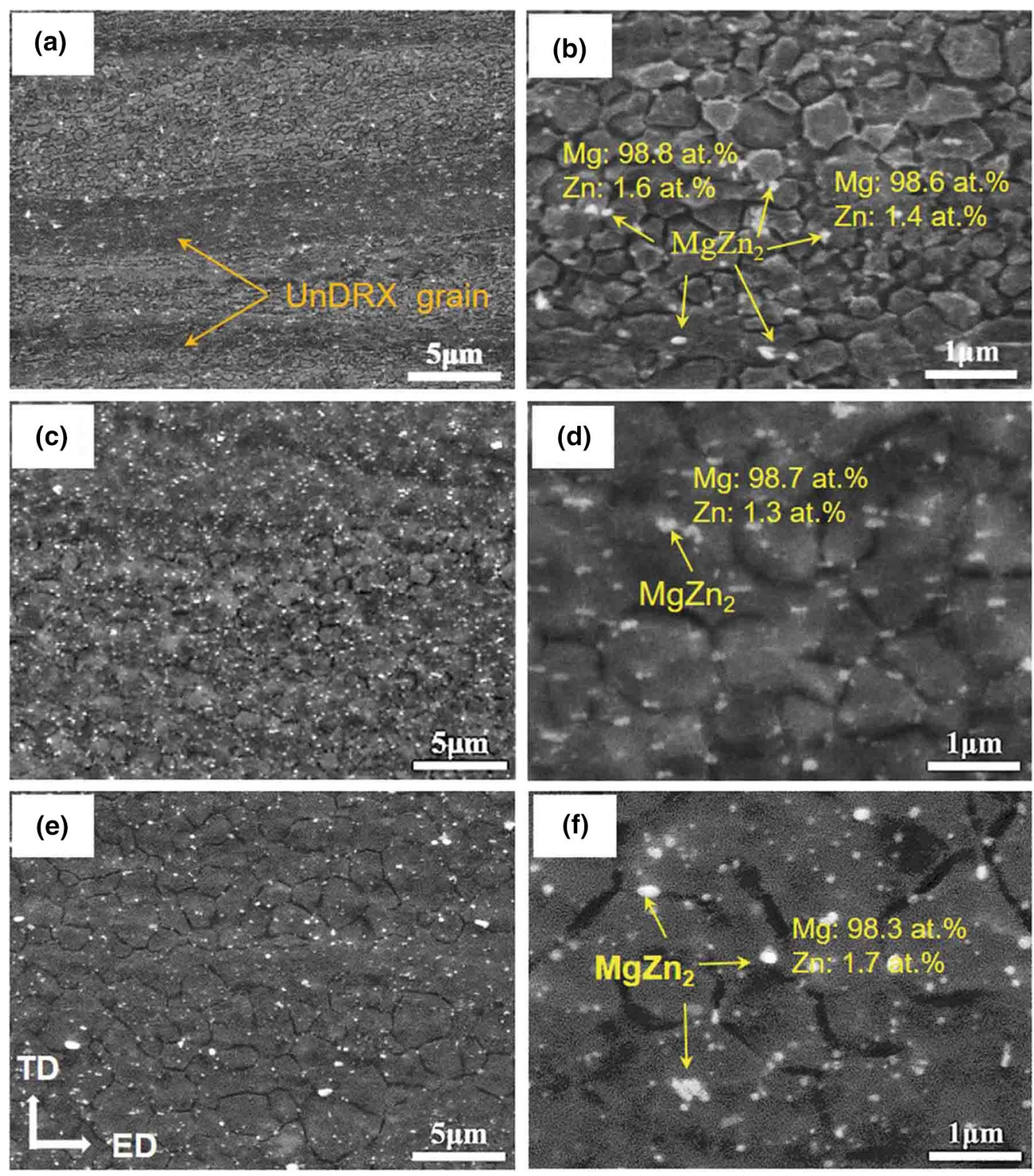

Fig. 5 Secondary electron images of a, b ZXM-270/0.01, c, d ZXM-270/1, e, f ZXM-350/0.01

the description of the images shown Fig. 4, during extrusion some second phases appear to be broken into fine particles. The phase composition of these fractured particles can be confirmed as $\mathrm{Ca}_{2} \mathrm{Mg}_{6} \mathrm{Zn}_{3}$ by both selected area electron diffraction (SAED) and EDS analysis (shown in Fig. 6a). Furthermore, fine DRXed grains appear located near fractured particles (Figs. 4b, 6a). Fine precipitates (marked by white circles, e.g., "A," in Fig. 6b) appear in grain boundaries and within grains which can be confirmed as $\mathrm{MgZn}_{2}$ based on EDS result (Fig. 6c) and SAED results. Further, Mn and $\mathrm{Mg}$ elements do not form compounds and Mn takes in the form of simple substance [15]. Xu et al. [28] reported that Mn takes the form of $\alpha-\mathrm{Mn}$ particles in the as-extruded $\mathrm{Mg}-5.99 \mathrm{Zn}-1.76 \mathrm{Ca}-0.35 \mathrm{Mn}$ alloy. In the present study, the particles marked by the yellow circle (e.g., "B," in Fig. 6b) in the TEM image contain mainly Mg and Mn (Fig. 6d). Thus, it can be deduced that $\alpha-\mathrm{Mn}$ particles exist in the present work by combining the EDS results and previous literature $[15,28]$. Both of the $\alpha-\mathrm{Mn}$ nanoparticles and finer $\mathrm{MgZn}_{2}$ precipitates can serve as obstacles and inhibit grain growth.

Generally, the DRXed grain size $\left(\bar{d}_{\mathrm{DRX}}\right)$ and DRX fraction $\left(V_{\mathrm{DRX}}\right)$ are affected by both the initial grain size in the as-cast condition and the extrusion parameters (extrusion speed and extrusion temperature). Since the initial grain size is kept constant prior to extrusion for the present ZXM alloy, variations in $\bar{d}_{\mathrm{DRX}}$ are mainly affected by the extrusion speed and extrusion temperature. The effect of extrusion 

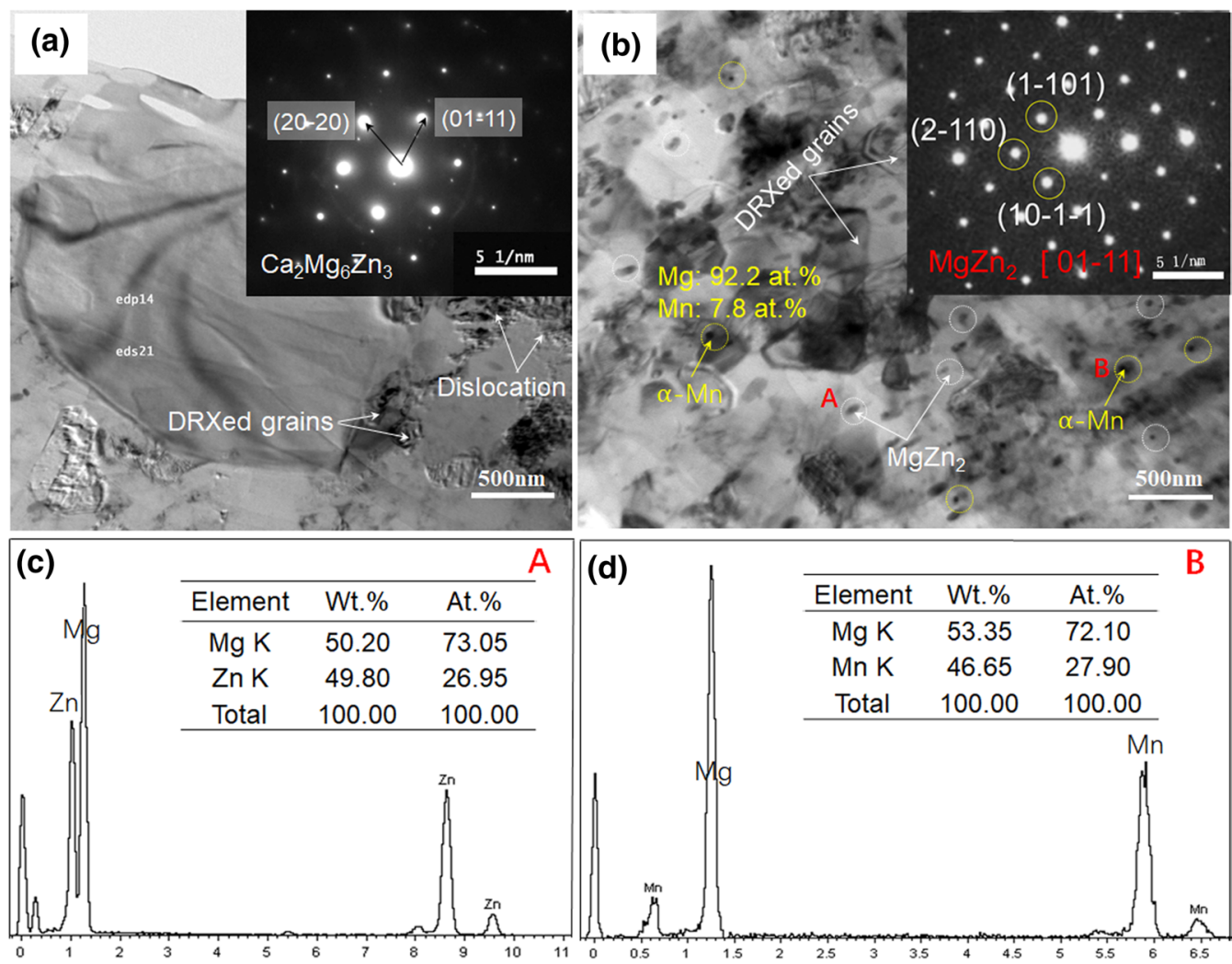

Fig. 6 Bright-field TEM images of ZXM-270/0.01 sample: a broken coarse phase, $\mathbf{b}$ distribution of second phases, $\mathbf{c}$ corresponding EDS point ("A" point, in b), $\mathbf{d}$ corresponding EDS point ("B" point, in b) (Inset in a shows the selected area diffraction pattern from the block phase, shown to be consistent with $\mathrm{Ca}_{2} \mathrm{Mg}_{6} \mathrm{Zn}_{3}$; inset in $\mathbf{b}$ shows the selected area diffraction pattern from the "A" point, shown to be consistent with $\mathrm{MgZn}_{2}$ )

parameters including temperature and strain rate, on the $\bar{d}_{\mathrm{DRX}}$, can be described by the Zener-Hollomon parameter (Z) [29]:

$Z=\dot{\varepsilon} \exp \left(\frac{Q}{R T}\right)$

where $R$ is the gas constant, $\dot{\varepsilon}, Q$ and $T$ represent the strain rate, activation energy and deformation temperature, respectively. The recrystallized grain size is related to $Z$ value, which can be expressed as [30]:

$Z d_{\mathrm{DRX}}^{m}=A$,

where $m$ represents the power law exponent and $A$ is a constant. According to Eq. (2), the grain size is decreased as $Z$ increases. As the deformation temperature decreases from 350 to $270{ }^{\circ} \mathrm{C}$, the value of $Z$ increases and DRXed grain size is refined in the ZXM-270/0.01 sample $(\sim 0.48 \mu \mathrm{m}$, Fig. 3c), which conforms to the description of the Zener-Hollomon parameter. However, the DRXed grain size increases from 0.48 to $0.9 \mu \mathrm{m}$ by increasing extrusion speed to $1 \mathrm{~mm} / \mathrm{s}$ (Fig. 3c, f), which is not consistent with the behavior described by the Zener-Hollomon parameter. A similar result has been reported in the $\mathrm{Mg}$ alloy extruded at high strain rates [1]. When the ram speed become faster, there is less time for heat dissipation, which increases the temperature experienced by the alloy during extrusion [31, 32] and contributes to grain growth. Besides, the variation in size and distribution of the second phases can also affect the DRXed grain size. On the one hand, particles larger than $1 \mu \mathrm{m}$, which are barely plastically deformed during extrusion [2], can induce local lattice rotations around the particles that promote recrystallization nucleation leading to smaller DRXed grains near the fractured particles (in Fig. 6). On the other hand, fine particles less than $1 \mu \mathrm{m}$ in size can inhibit DRXed grains growth due to their Zener pinning effect [1]. The volume fraction of precipitates significantly decreases ZXM-270/1 sample, resulting in a weakening of the pinning effects acting on the grain boundaries and so a larger grain size.

The volume fraction of DRX is related to the average strain rate $\dot{\bar{\varepsilon}}$, which can be described as [30]:

$\dot{\bar{\varepsilon}}=\frac{6 D_{\mathrm{B}}^{2} V_{\mathrm{R}} \ln \mathrm{ER}}{D_{\mathrm{B}}^{3}-D_{\mathrm{E}}^{3}}$,

where $V_{\mathrm{R}}$ is the extrusion speed, ER is extrusion ratio, $D_{\mathrm{B}}$ and $D_{\mathrm{E}}$ represent the diameters of the samples before and 
after extrusion, respectively. The $\dot{\bar{\varepsilon}}$ value increases with increasing the ram speed. The higher $\dot{\bar{\varepsilon}}$ can accelerate dislocation aggregation and lead to higher stored energy [33], which would promote DRX. Therefore, the volume fraction of DRX in ZXM-270/1 sample ( 66.9\%, in Fig. 3f) is much higher relative to the ZXM-270/0.01 sample $(\sim 29.8 \%$, in Fig. 3c).

The size and volume fraction of precipitates are also greatly affected by both extrusion speed and extrusion temperature. During extrusion, the formation of crystalline defects, such as dislocations and dense solute clusters [34], can facilitate the precipitation of second phases. Furthermore, dissolved Ca solute atoms can move by dislocationfacilitated pipe diffusion that act as fast diffusion path for solute clusters [10,35], which contributes to the formation of precipitates. Further, the slower extrusion speed means

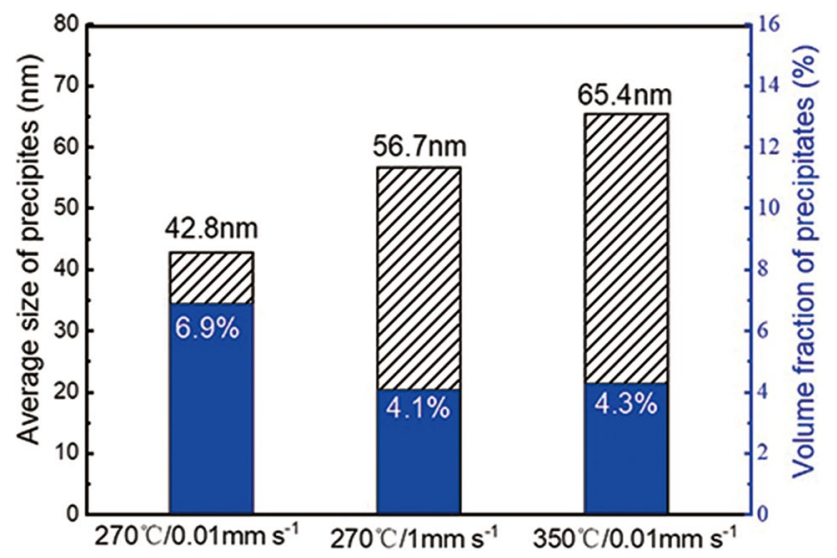

Fig. 7 Average size and volume fraction of $\mathrm{MgZn}_{2}$ phases in the ZXM alloys extruded under different conditions that there is longer time for the dynamic precipitation of the $\mathrm{MgZn}_{2}$ phase, resulting in larger volume faction of precipitates in $270{ }^{\circ} \mathrm{C} / 0.01 \mathrm{~mm} \mathrm{~s}^{-1}$ as shown in Fig. 7. In contrast, the higher extrusion temperature of $350{ }^{\circ} \mathrm{C}$ contributes to the growth of $\mathrm{MgZn}_{2}$ precipitates.

\subsection{Texture}

Figure 8a-c depicts the inverse pole figure (IPF) map and Schmid factor of ZXM-270/0.01 sample. The alloy exhibits a mixed grain microstructure containing the DRXed region (indicated by white arrows) and unDRXed region as shown in Fig. 8a. In the unDRXed coarse-grains regions, twin bands can be also observed as indicated by black arrows in Fig. 8a. As shown by the Schmid factor diagram in Fig. 8b, there are two peaks present for the as-extruded alloy with a mixed grain structure. The stronger peak (Schmid Factor of $\sim 0.45$ ) and weaker peak (Schmid Factor: 0.02) correspond to the DRXed fine-grain regions and unDRXed coarse-grains regions, respectively. There is a lower Schmid factor in the coarse deformed grains and a higher Schmid factor in DRXed fine-grain regions [36, 37]. The analysis of crystallographic orientations (in Fig. 8a) shows that the $\{0001\}$ basal planes of most deformed grains in the unDRXed coarse-grain regions are oriented parallel to the $E D$. The fine recrystallized grains are uniformly distributed with a random crystallographic orientation. There is a $<10$ $10>$ basal fiber texture for the overall microstructure of the alloy after extrusion (Fig. 8c).

The overall texture intensity is determined by all grains for the as-extruded ZXM alloy with mixed grain microstructure. The basal plane (0002), prismatic I (10-10) and prismatic II (11-20) regions of the entire specimens, recrystallized and unDRXed regions for the ZXM-270/0.01
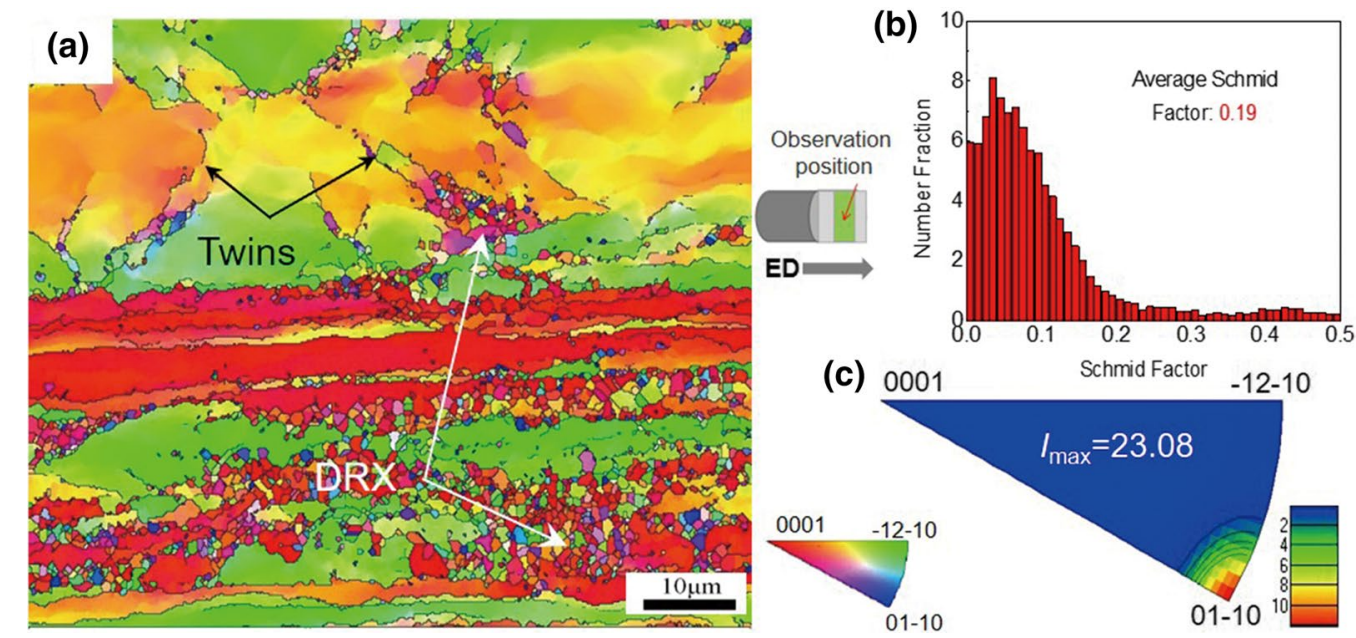

Fig. 8 Inverse pole figure map (IPF) of the ZXM-270/0.01 sample along extrusion direction: a IPF map, b Schmid factor, $\mathbf{c}$ inverse pole figure for overall region 

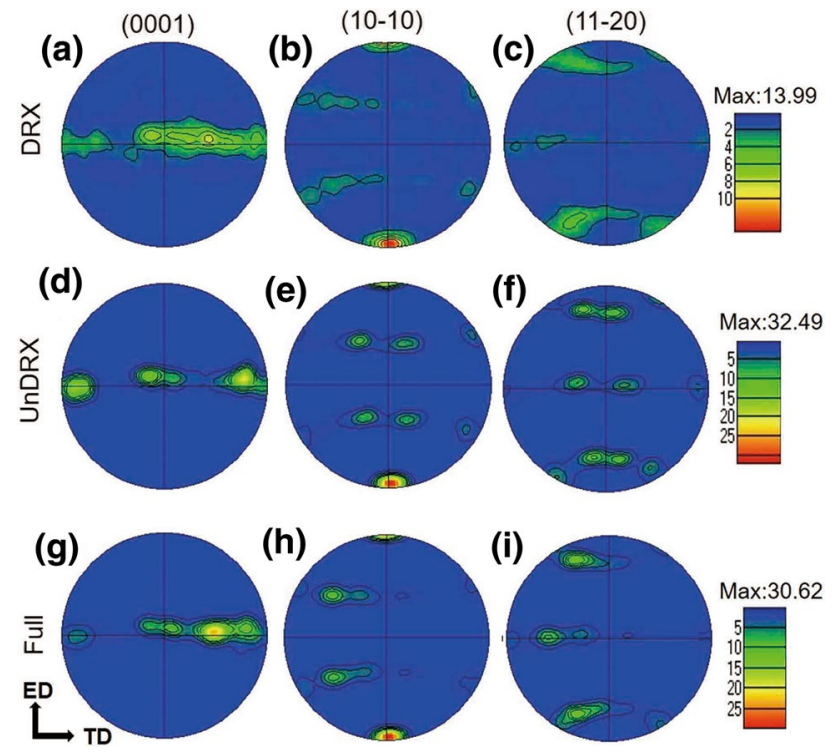

Fig. 9 Basal plane (0002), prismatic I (10-10) and prismatic II (1120) for the ZXM-270/0.01 sample: a-c DRXed fine-grain region, $\mathbf{d}-\mathbf{f}$ unDRXed coarse-grains region, $\mathbf{g}-\mathbf{i}$ overall

sample are presented in Fig. 9a-i. Overall, after extrusion, the maximum texture intensity $\left(I_{\max }\right)$ for all grains is determined as $\sim 30.62$ mud. For the DRXed fine-grain regions in Fig. 9a-c, the distribution of poles is broader with a weak texture $\left(I_{\max }: \sim 13.99\right.$ mud). In contrast, the preferential orientation for the unDRXed coarse-grain regions with a strong basal texture $\left(I_{\max }: \sim 32.49\right.$ mud in Fig. $\left.9 \mathrm{~d}-\mathrm{f}\right)$ are oriented toward ED, which is not conducive to the activation of basal slip under plastic deformation along the ED and results in a sharp fiber texture [38]. Zengin et al. [39] found that the crystal orientation of the coarse deformed grain in the as-extruded $\mathrm{Mg}-\mathrm{Zn}-\mathrm{Y}-\mathrm{La}-\mathrm{Zr}$ alloy was unconducive to the initiation of basal slip when the plastic deformation occurs along the extruded direction, which contributes to the formation of the fiber texture. As shown in Fig. $9 g-i$, the distribution of concentrated poles in the unDRXed coarsegrain regions is consistent with the overall structure, that exhibits a strong preferred orientation. The poles distribution of the DRXed fine-grain regions is disperse, and its texture intensity decreases to $\sim 13.99$ mud, which indicates that the basal planes of DRXed fine grains are inclined away from the ED. Consequently, it can be predicted that the unDRXed coarse grains contribute to stronger $<01-10>$ fiber texture in the as-extruded ZXM alloy (Fig. 8c).

Figure 10 presents an IPF map and kernel average misorientation (KAM) map of the ZXM-270/0.01 sample. As shown by the red dashed line in Fig. 10a, massive twins exist in the as-extruded alloy. The movement of dislocation can be inhibited by twins boundaries and unDRXed grain boundaries, contributing to the formation of dislocation cells. Meanwhile, the misorientation between the cells rapidly increased as the degree of plastic deformation increased and then changed into sub-grains [4]. In this study, massive low-angle grain boundaries (LAGBs) arose near twin bands and the front containing coarse deformed grains. Further, KAM analysis has been used to evaluate the level of stored energy, as presented in Fig. 10b. The colors represent the distribution of internal stored energy [40]. The blue color means that the region has a low stored energy and small dislocation density, while the red color indicates that the stress concentration and the pileups of dislocations. For the present $\mathrm{Mg}-\mathrm{Zn}-\mathrm{Ca}-\mathrm{Mn}$ alloys extruded at low speed $0.01 \mathrm{~mm} / \mathrm{s}$ with slow temperature of $270{ }^{\circ} \mathrm{C}$, a high stored energy zone near the twin bands and the coarse deformed grain front can be observed in Fig. 10b, suggesting dislocation pileups in these regions. This indicates that both twin bands and the coarse deformed grain front are the preferential nucleation of dynamic recrystallization in the ZXM alloy during extrusion.
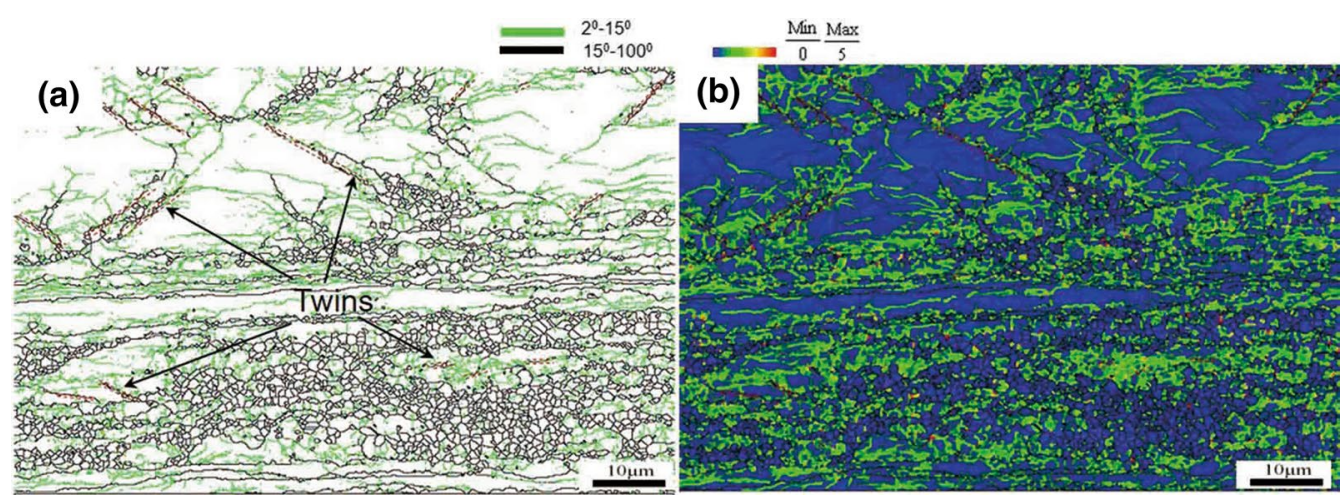

Fig. 10 a Inverse pole figure map, b kernel average misorientation (KAM) map of the ZXM-270/0.01 sample 

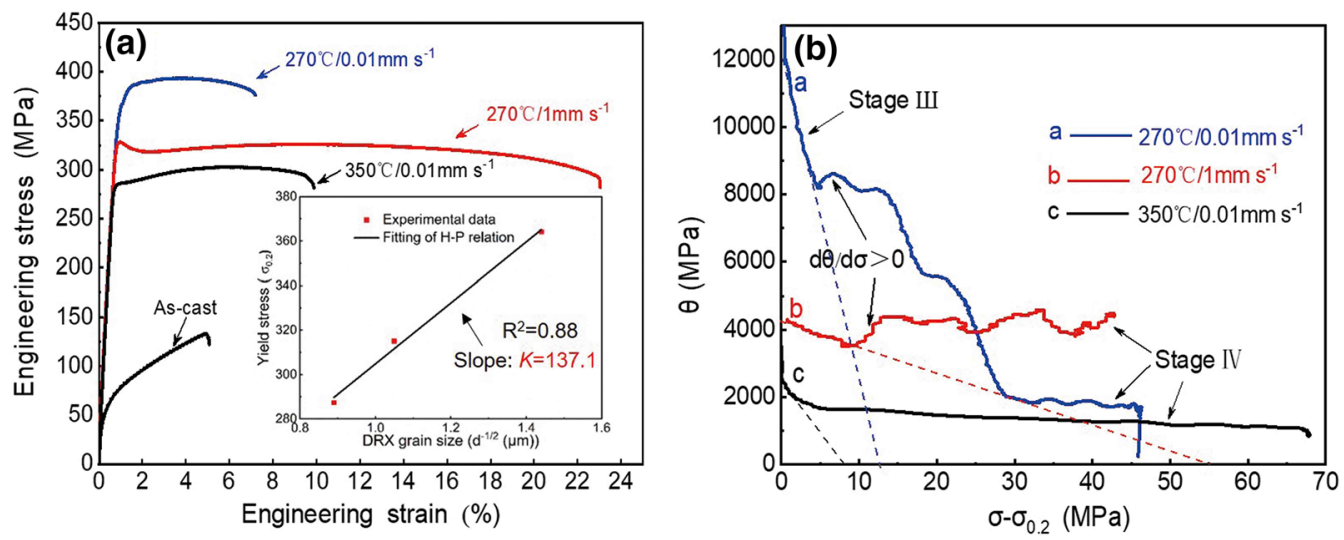

Fig. 11 a Engineering strain-stress curves, b strain hardening rate of the ZXM alloy extruded at different extrusion parameters

Table 1 Tensile properties of the as-cast and extruded ZXM alloys at different extrusion parameters

\begin{tabular}{lclr}
\hline Alloys & YS $(\mathrm{MPa})$ & UTS $(\mathrm{MPa})$ & \multicolumn{1}{c}{ EL $(\%)$} \\
\hline As-cast ZXM & $55.7 \pm 1.6$ & $131.6 \pm 10.1$ & $4.9 \pm 0.7$ \\
ZXM-270/0.01 & $364.1 \pm 4.6$ & $394.5 \pm 8.5$ & $7.2 \pm 0.9$ \\
ZXM-270/1 & $315.0 \pm 11.1$ & $318.9 \pm 8.8$ & $23.1 \pm 2.3$ \\
ZXM-350/0.01 & $287.3 \pm 1.5$ & $303.3 \pm 0.9$ & $9.8 \pm 0.2$ \\
\hline
\end{tabular}

\subsection{Mechanical Properties}

Figure 11 shows the engineering stress-strain curves and strain hardening rate curves of the ZXM alloys. Table 1 lists the corresponding values of ultimate tensile strength (UTS), yield strength (YS) and elongation to failure (EL). Excellent performance including a YS of $364.1 \mathrm{MPa}$, a UTS of $\sim 394.5 \mathrm{MPa}$ and a EL of $\sim 7.2 \%$ are achieved in the ZXM-270/0.01 sample, which is much higher relative to as-cast counterpart. As shown in Fig. 12, the strength of the mixed grain-structure ZXM-270/0.01 sample with a high $\mathrm{Ca}$ and low Zn concentration is higher relative to as-extruded AZ alloy series [41-43], $\mathrm{Mg}-\mathrm{Sn}$ alloys [31, 44, 45], other $\mathrm{Mg}-\mathrm{Zn}$ alloys extruded at higher temperatures (above $300{ }^{\circ} \mathrm{C}$ ) or higher extrusion speeds (above $\sim 10 \mathrm{~mm} / \mathrm{s}$ ) $[14,21]$ and a $\mathrm{Mg}-4 \mathrm{Zn}-0.5 \mathrm{Ca}$ (wt\%) alloy extruded at $280{ }^{\circ} \mathrm{C} / 0.01 \mathrm{~mm} \mathrm{~s}^{-1}$ with a high $\mathrm{Zn}$ and low Ca concentration [1]. Furthermore, the YS of the present $270{ }^{\circ} \mathrm{C} / 0.01 \mathrm{~mm} \mathrm{~s}^{-1}$ sample is even greater than that for a number of Mg-Re alloys [20, 46-49].

This increment in YS for the present ZXM alloy can be attributed to the mixed grain structure containing unDRXed coarse-grain regions, DRXed fine-grain regions (in Fig. 3) and numerous nano-scale dynamic precipitates (in Fig. 7). Thus, the yield strength $\left(\sigma_{\mathrm{y}}\right)$ can be estimated by [3]:
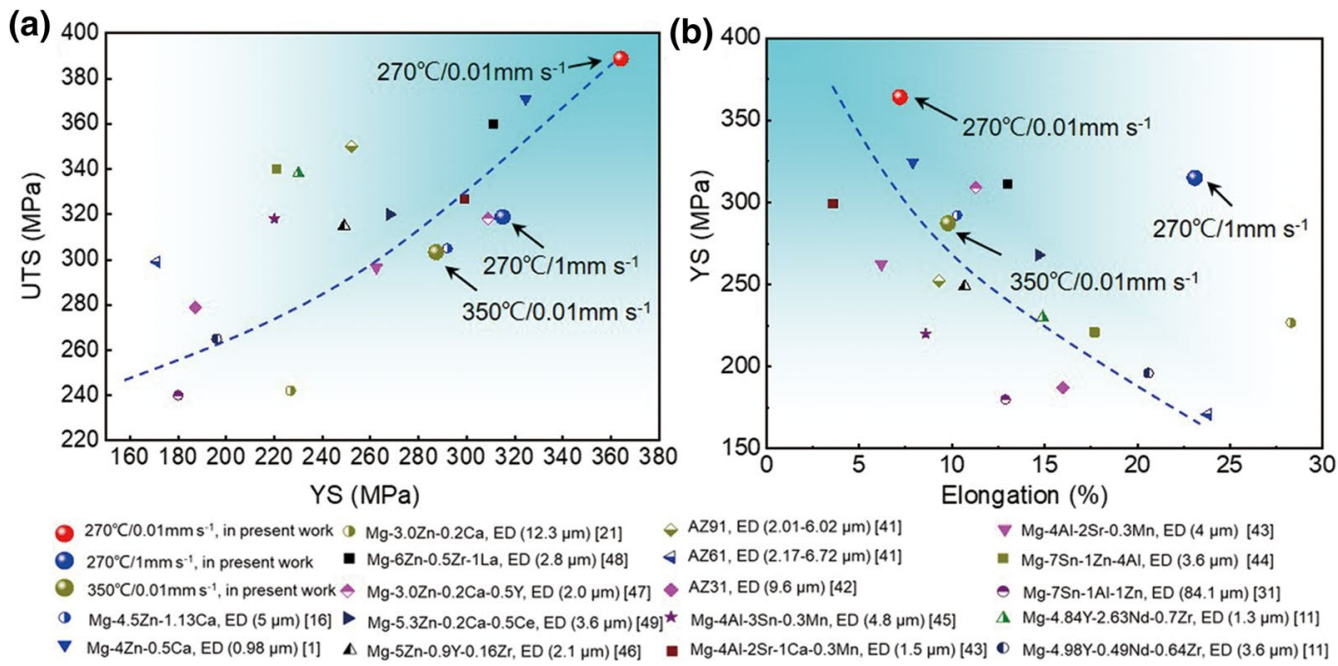

Fig. 12 Comparison of mechanical properties among the present ZXM alloys extruded at different conditions and previous works: a UTS versus YS, b YS versus elongation 
$\sigma_{\mathrm{y}}=f_{\mathrm{DRX}} \Delta \sigma_{\mathrm{y}, \mathrm{DRX}}+f_{\mathrm{unDRX}} \Delta \sigma_{\mathrm{y}, \mathrm{unDRX}}$,

where $\Delta \sigma_{\mathrm{y}, \mathrm{DRX}}$ represents the contribution resulting from DRXed fine-grain regions, $\Delta \sigma_{\mathrm{y} \text {, unDRX }}$ represents the contribution from unDRXed coarse-grains regions. $f_{\mathrm{DRX}}$ is the volume fraction of DRX, $f_{\text {unDRX }}$ is the remaining volume fraction of unDRXed regions. There are fewer dislocations in the DRXed fine-grain regions and a high dense of dislocations in the unDRXed coarse-grain regions (Fig. 6a), but the texture density is also different, so the yield strength $\left(\sigma_{\mathrm{y}}\right)$ for DRXed fine-grain regions and unDRXed coarsegrain regions should be discussed separately, which can be expressed as [10]:

$\sigma_{\mathrm{y}, \mathrm{DRX}}=\Delta \sigma_{\mathrm{gb}}+M_{\mathrm{DRX}}\left(\tau_{0}+\Delta \tau_{\mathrm{s}}+\Delta \tau_{\text {Orowan }}\right)$,

$\sigma_{\mathrm{y}, \text { unDRX }}=M_{\mathrm{unDRX}}\left(\tau_{0}+\Delta \tau_{\mathrm{s}}+\Delta \tau_{\text {Orowan }}+\Delta \tau_{\mathrm{d}}\right)$,

where $\Delta \sigma_{\mathrm{gb}}$ stands for the increment of the YS affected by grain refinement, $\tau_{0}$ represents the intrinsic critical resolved shear stresses (CRSS), $\Delta \tau_{\mathrm{s}}$ is the CRSS resulted from solid solution strengthening, $\Delta \tau_{\text {Orowan }}$ is the CRSS resulted from Orowan strengthening, and $\Delta \tau_{\mathrm{d}}$ is the CRSS resulted from dislocation strengthening. $M$ is the Taylor factor, and this value is associated with the intensity of the texture $[3,10]$ : the unDRXed coarse-grain regions generally present a strong texture, and the value of $M$ varies from 2.1 to 3.5, while the DRX region exhibits a weak texture and the value of $M$ ranges from 4 to 5.5. In this study, the value of $M_{\mathrm{DRX}}$ was taken as 5 for the DRXed fine-grain regions and the corresponding $M_{\text {unDRX }}$ was taken as 3.5 for the unDRXed coarse-grains regions.

With respect to the present as-extruded alloy, the solid solution strengthening intrinsic strength can be considered as $\sigma_{0}$ because the contribution of solid solution strengthening was limited for the improved YS of the alloy and barely changed before and after extrusion. The value of $\sigma_{0}$ can be taken as $\sim 55.7 \mathrm{MPa}$ based on the YS of the as-cast ZXM (Table 1). Besides, $\mathrm{MgZn}_{2}$ are precipitated for both coarse deformed and fine DRXed regions (Fig. 5). Thus, the improved yield strength related to the DRXed fine-grain and unDRXed coarse-grain regions were described as follows:

$\sigma_{\mathrm{y}, \mathrm{DRX}}=\sigma_{0}+\Delta \sigma_{\mathrm{gb}}+M_{\mathrm{DRX}} \Delta \tau_{\text {Orowan }}$,

$\sigma_{\mathrm{y}, \text { unDRX }}=\sigma_{0}+M_{\text {unDRX }}\left(\Delta \tau_{\text {Orowan }}+\Delta \tau_{\mathrm{d}}\right)$.

The grain refinement strengthening after extrusion can be described as [1]:

$\Delta \sigma_{\mathrm{gb}}=k d^{-1 / 2}$, where the value of Hall-Petch coefficient $k$ is 137.1 MPa $\mu \mathrm{m}^{1 / 2}$ (from Fig. 11a), $d$ represents the average size of recrystallized small grains for the as-extruded ZXM alloy, and the values is given in Fig. 3. The values of $\Delta \sigma_{\mathrm{gb}}$ for each extruded alloy are $197.8 \mathrm{MPa}$ $\left(270{ }^{\circ} \mathrm{C} / 0.01 \mathrm{~mm} \mathrm{~s}^{-1}\right), 144.5 \mathrm{MPa}\left(270{ }^{\circ} \mathrm{C} / 1 \mathrm{~mm} \mathrm{~s}^{-1}\right)$ and $106.3 \mathrm{MPa}\left(350^{\circ} \mathrm{C} / 0.01 \mathrm{~mm} \mathrm{~s}^{-1}\right)$ according to Eq. (9).

In addition, there are a large number of fine precipitates less than $1 \mu \mathrm{m}$ in size as shown in Fig. 7. The pinning effect of these precipitates on the dislocation movement can be described by Orowan strengthening [14, 50]:

$\Delta \tau_{\text {Orowan }}=\frac{0.4 G b}{\pi \bar{\lambda}} \frac{\ln \left(\frac{\bar{d}}{b}\right)}{\sqrt{1-v}}$,

$\bar{\lambda}=\bar{d}(\sqrt{\pi / 4 f}-1)$,

where $G$ represents shear modulus ( $16.5 \mathrm{GPa}$ ), the values of Burgers vector $b$ and Poisson's ratio $v$ are $0.32 \mathrm{~nm}$ and 0.35 , respectively. $\bar{d}$ is the average diameter of $\mathrm{MgZn}_{2}$ phases, while $f$ is the volume fraction. The relevant data was presented in Fig. 7. The calculated values of $\Delta \tau_{\text {Orowan }}$ for the ZXM-270/0.01, ZXM-270/1 sample and ZXM-350/0.01 sample, respectively, are $52.3 \mathrm{MPa}, 29.8 \mathrm{MPa}$ and $27.4 \mathrm{MPa}$ according to Eqs. (10) and (11).

The dislocation strengthening $\left(\Delta \tau_{\mathrm{d}}\right)$ which is affected by dislocation density, can be calculated by the following formula [3]:

$\Delta \tau_{\mathrm{d}}=\alpha G b \sqrt{\rho}$,

where the value of constant $\alpha$ is 0.2 , and the value of dislocation density $\rho$ is around $10^{14} \mathrm{~m}^{-2}-10^{16} \mathrm{~m}^{-2}$ for a severely deformed metal [3]. In present work, the value of $\rho$ is estimated as $2 \times 10^{14} \mathrm{~m}^{-2}$ for the alloy in the unDRXed coarsegrains regions after extrusion. Accordingly, the $\Delta \tau_{\mathrm{d}}$ is calculated from Eq. (12) and its value is $15 \mathrm{MPa}$.

The theoretical YS for the ZXM-270/0.01, ZXM-270/1 sample and ZXM-350/0.01 samples, respectively, can be predicted using Eq. (4) to be: $0.298 \times 515.0+0.702 \times 291$. $2=357.9 \mathrm{MPa}, 0.669 \times 349.2+0.331 \times 212.5=303.9 \mathrm{MPa}$, $0.534 \times 296.9+0.466 \times 04.1=253.6 \mathrm{MPa}$. Figure 13 shows the calculated values and experimental data for the YS of asextruded ZXM alloys. As shown in Fig. 13a, among the four strengthening mechanisms, fine grain strengthening contributes the most in increasing the YS of the extruded ZXM alloys. For the alloy extruded at $270{ }^{\circ} \mathrm{C} / 0.01 \mathrm{~mm} \mathrm{~s}^{-1}$, it exhibits a mixed grain structure containing unDRXed coarsegrains regions and DRXed fine-grain regions and shows an excellent strength of YS $364.1 \mathrm{MPa}$ and EL $\sim 7.2 \%$. The fine grain strengthening resulted from DRXed fine-grain region plays a higher contribution compared with dislocation 

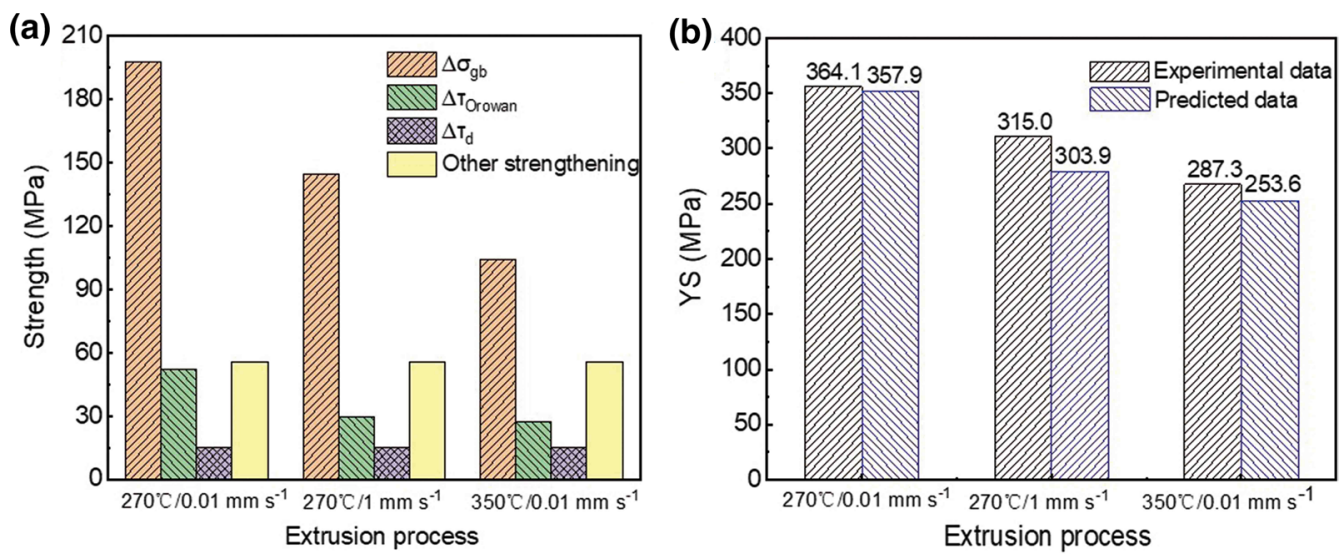

Fig. 13 a Comparison strengthening mechanisms, $\mathbf{b}$ comparison of YS among the experimental data and predicted data

strengthening caused by the unDRXed region and Orowan strengthening, suggesting that the refinement of the grain size is more significant to improve the strength of the alloy. As shown in Fig. 13b, it is evident that the calculated values are close to the experimental data. The predicted strength is lower than experimental strength. This may be due to that strengthening effect caused by extremely fine precipitates in the TEM image (Fig. 6b) is neglected. Further, based on some published literatures, back stress strengthening can be generated in the magnesium alloys with bimodal grain structures [51, 52]. For instance, Zhang et al. [53] found that for a $\mathrm{Mg}-\mathrm{Al}-\mathrm{Sn}-\mathrm{Zn}$ alloy with a bimodal grain microstructure, to accommodate the incompatibility between fine DRXed grains and coarse deformed grains, geometrically necessary dislocations and back stresses could generate in the coarse deformed grains, which can generate back stress strengthening. If the above strengthening can be accurately calculated, the predicted strength should be higher than experimental strength.

The small differences between the calculated value and the experimental data can be mainly attributed to the omission of precipitate strengthening generated by the fine precipitates as shown in the TEM s (Fig. 6b).

The work hardening behavior can be analyzed to illustrate the tensile ductility of as-extruded alloy, especially for the work hardening rate $(\theta)$, which is described as [35]:

$\theta=\frac{\mathrm{d} \sigma}{\mathrm{d} \varepsilon}$

where $\sigma$ and $\varepsilon$ stand for true stress and true strain, respectively. From Fig. 11b, it can be found that there are two stages for the as-extruded ZXM alloy, which consists of the dynamic recovery stage (stage III) and large strain work hardening stage (stage IV). As can be observed in Fig. 11b, there is a positive work hardening rate $(\mathrm{d} \theta / \mathrm{d} \sigma>0)$ at the early part of stage III for the alloy extruded at $270{ }^{\circ} \mathrm{C}$, which indicates that twinning-dominated deformation mechanism exists. In the case of $\mathrm{Mg}$ alloys extruded at low temperature, the alloy possesses a sharp fiber texture as shown in Fig. 8 and twins plays a vital role in deformation due to the insufficient number of slip systems [54]. \{10-12\} twinning can be usually detected in cold extruded $\mathrm{Mg}$ alloys because of its low critical resolved shear stress [21], which can act as a source of work hardening. During tensile deformation, the movement of dislocations is prone to be suppressed by grain boundaries, second phase as well as twin boundaries. The relaxation time $(\tau)$ required for dislocation dissociation into grain boundaries were demonstrated as [55]:

$\tau=\frac{\rho b d}{\alpha \bar{\varepsilon}}$

where $\rho, \bar{\varepsilon}$ and $d$ are the dislocation density, strain rate and grain size, respectively. $\alpha$ represents a geometrical term associated with the contributions from active dislocations. According to Eq. (14), the smaller grain size is conducive to dislocation slipping to grain boundaries and results in a rapidly increased dynamic recovery rate. For the current ZXM-270/0.01 sample, the smallest DRXed grain $(\sim 0.48 \mu \mathrm{m})$ contributes to a faster decrease in the value of $\theta$ (at stage III, in Fig. 11b) relative to that of ZXM-270/1 sample and ZXM-350/0.01 counterparts. The precipitates can suppress the movement of dislocations resulting in a decrease in dynamic recovery rate [56]. As depicted in Fig. 7, the size of the $\mathrm{MgZn}_{2}$ precipitates in $\mathrm{ZXM}-270 / 1$ sample is much smaller than that in the ZXM-350/0.01 sample. The suppression effect of dislocation movement caused by precipitates in ZXM-270/1 sample is remarkable relative to the ZXM-350/0.01 counterpart, resulting in a $\theta$ value that decreases slowly. The strain hardening at stage IV represents the initiation of multiple slip as strain increases during the tensile test [36]. The highest $\theta$ value at stage IV was obtained in ZXM-270/1 sample as shown in Fig. 11b, which is related to the large DRXed grain size and smaller 
precipitates. On the one hand, the interactions between dislocation and boundaries would be reduced for an alloy with a larger grain size [57]. On the other hand, the strain hardening after yielding caused by dynamic precipitates is affected by dislocation strain field interactions, which can be described as [55]: $\sigma-\sigma_{\mathrm{YS}} \approx \sigma_{\mathrm{d}} \propto \sqrt{\rho}$. The resistance to dislocation slip resulting from dislocation interactions tends to be more pronounced with the increase in dislocation density. The relatively large DRXed grain size $(\sim 0.90 \mu \mathrm{m})$ and fine precipitates for the ZXM-270/1 sample are conducive to dislocation accumulation, promoting work hardening. The investigation of Narayanasamy et al. [58] on a ZM21 alloy showed that a high work hardening can effectively distribute the plastic deformation and so delay necking, resulting in uniform elongation. A similar result was reported in $\mathrm{Du}$ et al. [14] on a $\mathrm{Mg}-4.50 \mathrm{Zn}-1.13 \mathrm{Ca}$ (wt\%) alloy. The higher amount of work hardening leads to significant elongation ( 23.1\%) for the ZXM-270/1 sample.

\subsection{Fracture Observation}

Figure $14 \mathrm{a}-\mathrm{i}$ shows $\mathrm{OM}$ images near fracture surfaces and SEM images of ZXM alloys extruded under different conditions. Twins appear in all the as-extruded alloys as shown in Fig. 14a, d, g. For the as-extruded alloys of a strong fiber texture, as the contraction strain component is parallel to the $c$-axis, the $\{10-11\}$ contraction twins and $\{10-11\}-\{10-12\}$ double twins are readily nucleated in the coarser deformed grains $[59,60]$. As presented in Fig. $14 \mathrm{a}, \mathrm{b}$, there are many cracks in the twinned grains. Thus, the cracking along the twins can be considered as one of the main fracture mechanisms for the ZXM270/0.01 sample. As illustrated in Fig. 14e, f, the volume fraction of twins clearly decreased with increasing extrusion speed, while the fraction of dimples present increased. This can be attributed to the relatively fine DRXed grain size $(\sim 0.90 \mu \mathrm{m})$ and high $V_{\mathrm{DRX}}(\sim 66.9 \%)$ giving rise to a weaker texture, which promotes dislocation slip and so enhances plasticity $[61,62]$. For the ZXM$350 / 0.01$ sample, it exhibits the largest recrystallized grain size $(\sim 1.24 \mu \mathrm{m})$ and low volume faction of DRXed grains ( $\sim 53.4 \%$, in Fig. 3i), which is unfavorable for dislocation slip resulting in a poor plasticity. Besides, the lowest work hardening $\theta$ value at last stage IV appeared in ZXM350/0.01 sample (Fig. 11b), is not effective in distributing the plastic deformation to delay necking, which gives rise to deteriorating elongation. Further, the fracture morphology of the ZXM-350/0.01 sample (in Fig. 14h, i) exhibits

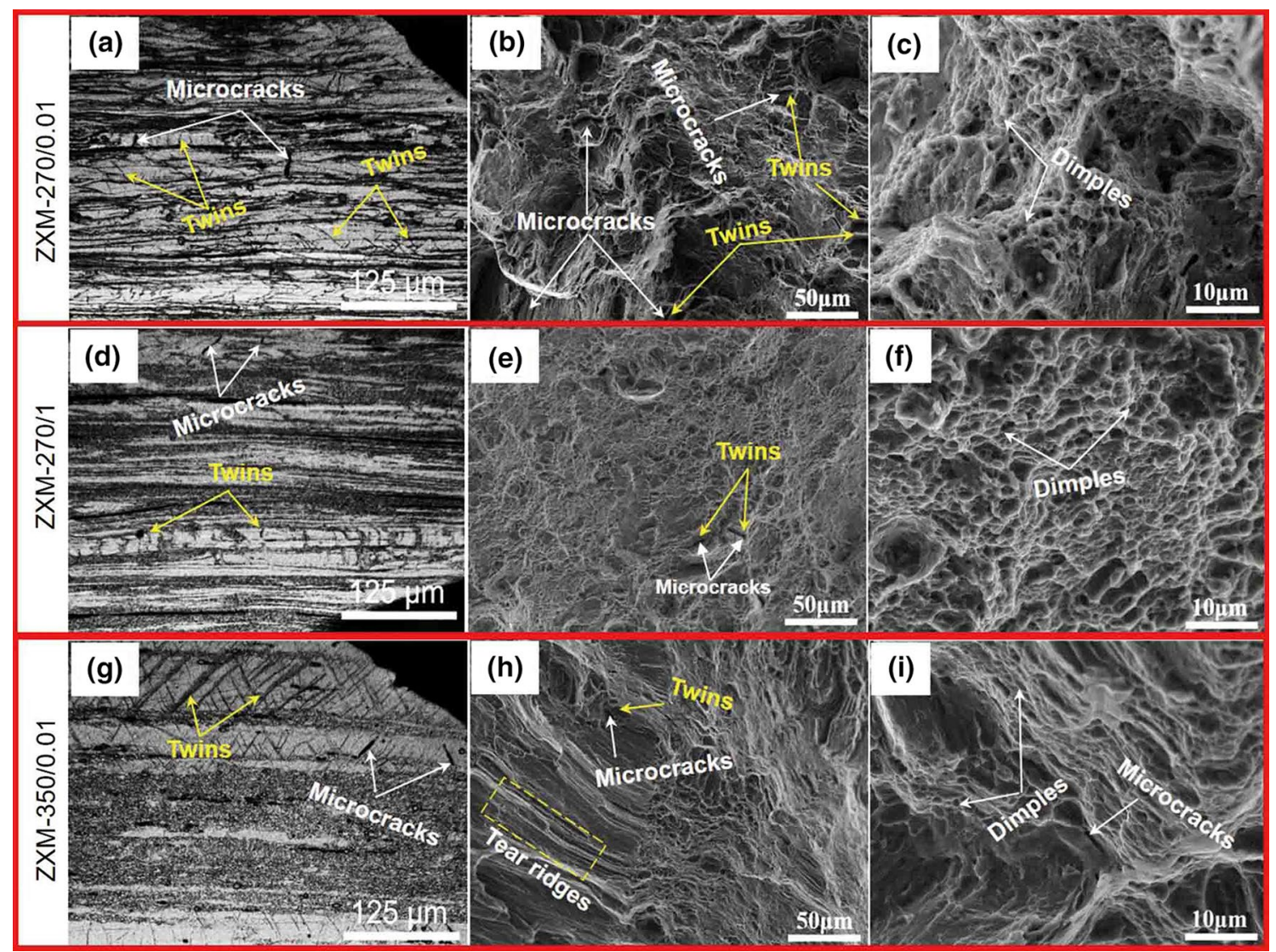

Fig. 14 OM near fracture surfaces as well as the typical SEM surfaces of $\mathbf{a}-\mathbf{c}$ ZXM-270/0.01, d-f ZXM-270/1, $\mathbf{g}-\mathbf{i}$ ZXM-350/0.01 
a mixed ductile-brittle fracture, which is consistent with a mixed fracture surface consisting of typical brittle fracture (tearing ridges, marked with yellow dotted frame) and ductile fracture (dimples, marked with white arrows). There are massive micro-cracks caused by twins in the coarse unDRXed grains for ZXM-350/0.01 sample as shown in Fig. $14 \mathrm{~g}$, h. As a result, the appearance of micro-cracks resulted from twins in coarse-deformed grains, the largest size and low volume faction of DRXed grains, as well as the lowest $\theta$ value at stage IV leads to the failure of the alloy during tension, decreasing the plasticity.

\section{Conclusions}

In this present work, a $\mathrm{Mg}-2.2 \mathrm{Zn}-1.8 \mathrm{Ca}-0.5 \mathrm{Mn}$ alloy has been newly developed and subjected to a range of extrusion conditions. The conclusions are drawn based on its microstructures and mechanical properties as follows:

(1) With the decrease in the speed from 1 to $0.01 \mathrm{~mm} / \mathrm{s}$ or the extrusion temperature from 350 to $270{ }^{\circ} \mathrm{C}$, DRXed grain size gradually decreases. The smallest bimodal DRXed grain structure in the ZXM-270/0.01 sample can be attributed to a large $Z$ value and pinning effects of nano-sized $\mathrm{MgZn}_{2}$ precipitates and $\alpha$-Mn nanoparticles.

(2) The overall region which is composed of unDRXed coarse-grain region and DRXed grain region exhibits an intense preferred orientation. A stronger texture intensity of $\sim 32.49$ mud appears in the unDRXed coarse-grain region, while more random orientation and weaker texture intensity of $\sim 13.99$ mud is obtained in the DRXed grain region.

(3) The alloy extruded $270{ }^{\circ} \mathrm{C}$ exhibits a positive slope of work hardening rate $(\mathrm{d} \theta / \mathrm{d} \sigma>0)$, which is related to sharp basal texture and insufficient slip systems. High $\theta$ values at stage IV of strain hardening for the alloy extruded $270{ }^{\circ} \mathrm{C} / 1 \mathrm{~mm} \mathrm{~s}^{-1}$ with abundant dimples and weak texture contribute to a high ductility.

(4) The ZXM-270/0.01 sample exhibits a YS of 364.1 MPa, UTS of $394.5 \mathrm{MPa}$ and EL of $7.2 \%$. The fine grain strengthening resulting from DRXed fine-grain region plays a higher contribution relative to dislocation strengthening caused by the unDRXed region and Orowan strengthening.

Acknowledgements This work was financially supported by the National Natural Science Foundation of China (Nos. 51771129, 51401144 and 51771128), the Program for the Outstanding Innovative Teams of Higher Learning Institutions of Shanxi, the Natural Science Foundation of Shanxi Province (Nos. 2015021067 and 201601D011034), the special fund project for guiding local science and technology development by the central government (YDZX20191400002734), the Projects of International Cooperation in Shanxi (No. 201703D421039) and the China Scholarship Council.

\section{References}

[1] W.J. Li, K.K. Deng, X. Zhang, K.B. Nie, F.J. Xu, Mater. Sci. Eng. A 677, 367 (2016)

[2] Y.Z. Du, M.Y. Zheng, X.G. Qiao, K. Wu, X.D. Liu, G.J. Wang, X.Y. Lv, M.J. Li, X.L. Liu, Z.J. Wang, Y.T. Liu, Mater. Sci. Eng. A 583, 69 (2013)

[3] X.K. Kang, K.B. Nie, K.K. Deng, Y.C. Guo, Mater. Charact. 151, 137 (2019)

[4] B.J. Wang, D.K. Xu, S.D. Wang, L.Y. Sheng, R.C. Zeng, E.H. Han, Int. J. Fatigue 120, 46 (2019)

[5] G. Levi, S. Avraham, A. Zilberov, M. Bamberger, Acta Mater. 54, $523(2006)$

[6] Q. Kang, H. Jiang, Y. Zhang, Z. Xu, H. Li, Z. Xia, J. Alloys Compd. 742, 1019 (2018)

[7] J.D. Robson, C. Paa-Rai, Acta Mater. 95, 10 (2015)

[8] M. Kaviani, G.R. Ebrahimi, H.R. Ezatpour, Mater. Chem. Phys. 234, 245 (2019)

[9] L.B. Tong, M.Y. Zheng, S.W. Xu, S. Kamado, Y.Z. Du, X.S. Hu, K. Wu, W.M. Gan, H.G. Brokmeier, G.J. Wang, X.Y. Lv, Mater. Sci. Eng. A 528, 3741 (2011)

[10] Y.Z. Du, X.G. Qiao, M.Y. Zheng, D.B. Wang, K. Wu, I.S. Golovin, Mater. Des. 98, 285 (2016)

[11] S.W. Xu, K. Oh-ishi, S. Kamado, T. Homma, Scr. Mater. 65, 875 (2011)

[12] S. Shuai, E. Guo, J. Wang, A.B. Phillion, T. Jing, Z. Ren, P.D. Lee, Acta Mater. 156, 287 (2018)

[13] K. Oh-ishi, R. Watanabe, C.L. Mendis, K. Hono, Mater. Sci. Eng. A 526, 177 (2009)

[14] Y.Z. Du, M.Y. Zheng, C. Xu, X.G. Qiao, K. Wu, X.D. Liu, G.J. Wang, X.Y. Lv, Mater. Sci. Eng. A 576, 6 (2013)

[15] M.G. Jiang, C. Xu, T. Nakata, H. Yan, R.S. Chen, S. Kamado, Mater. Sci. Eng. A 678, 329 (2016)

[16] B. Zhang, Y. Wang, L. Geng, C. Lu, Mater. Sci. Eng. A 539, 56 (2012)

[17] J.W. Kang, C.J. Wang, K.K. Deng, K.B. Nie, Y. Bai, W.J. Li, J. Alloys Compd. 720, 196 (2017)

[18] J. Hofstetter, S. Rüedi, I. Baumgartner, H. Kilian, B. Mingler, E. Povoden-Karadeniz, S. Pogatscher, P.J. Uggowitzer, J.F. Löffler, Acta Mater. 98, 423 (2015)

[19] S. Yin, Z. Zhang, X. Liu, Q. Le, Q. Lan, L. Bao, J. Cui, Mater. Sci. Eng. A 695, 135 (2017)

[20] X. Xu, X. Chen, W. Du, Y. Geng, F. Pan, J. Mater. Sci. Technol. 33, 926 (2017)

[21] C.J. Li, H.F. Sun, X.W. Li, J.L. Zhang, W.B. Fang, Z.Y. Tan, J. Alloys Compd. 652(122), 122-131 (2015)

[22] K. Nie, X. Kang, K. Deng, Y. Guo, J. Han, Z. Zhu, J. Mater. Res. 33, 2806 (2018)

[23] N.C. Verissimo, C. Brito, C.R. Afonso, J.E. Spinelli, N. Cheung, A. Garcia, Mater. Chem. Phys. 204, 105 (2018)

[24] M. Yang, T. Guo, H. Li, Mater. Sci. Eng. A 587, 132 (2013)

[25] L.D. Wang, X.S. Li, C. Wang, L.M. Wang, Z.Y. Cao, Trans. Nonferrous Met. Soc. China 26, 704 (2016)

[26] Y. Chen, L. Jin, J. Dong, Z. Zhang, F. Wang, Mater. Charact. 118, 363 (2016)

[27] D. Guan, W.M. Rainforth, L. Ma, B. Wynne, J. Gao, Acta Mater. 126, 132 (2017)

[28] S.W. Xu, K. Oh-ishi, H. Sunohara, S. Kamado, Mater. Sci. Eng. A 558, 356 (2012) 
[29] K.K. Deng, C.J. Wang, K.B. Nie, Acta Metall. Sin. (Engl. Lett.) 32, 413 (2019)

[30] J.W. Kang, X.F. Sun, K.K. Deng, F.J. Xu, X. Zhang, Y. Bai, Mater. Sci. Eng. A 697, 211 (2017)

[31] S.H. Park, S.H. Kim, H.S. Kim, J. Yoon, B.S. You, J. Alloys Compd. 667, 170 (2016)

[32] X. Sun, C.J. Wang, K.K. Deng, K.B. Nie, X.C. Zhang, X.Y. Xiao, J. Alloys Compd. 732, 328 (2018)

[33] L.B. Tong, M.Y. Zheng, L.R. Cheng, S. Kamado, H.J. Zhang, Mater. Sci. Eng. A 569, 48 (2013)

[34] A. Deschamps, G. Fribourg, Y. Bréchet, J.L. Chemin, C.R. Hutchinson, Acta Mater. 60, 1905 (2012)

[35] H. Pan, G. Qin, Y. Huang, Y. Ren, X. Sha, X. Han, Z.Q. Liu, C. Li, X. Wu, H. Chen, C. He, L. Chai, Y. Wang, J.F. Nie, Acta Mater. 149, 350 (2018)

[36] S.W. Xu, K. Oh-ishi, S. Kamado, F. Uchida, T. Homma, K. Hono, Scr. Mater. 65, 269 (2011)

[37] K. Sheng, L.W. Lu, Y. Xiang, M. Ma, Z.C. Wang, Acta Metall. Sin. (Engl. Lett.) 32, 235 (2019)

[38] T. Tu, X.H. Chen, J. Chen, C.Y. Zhao, F.S. Pan, Acta Metall. Sin. (Engl. Lett.) 32, 23 (2019)

[39] H. Zengin, Y. Turen, M.E. Turan, F. Aydın, Acta Metall. Sin. (Engl. Lett.) 32, 1309 (2019)

[40] M.S. Kim, S.H. Kim, H.W. Kim, Scr. Mater. 152, 69 (2018)

[41] S.H. Kim, B.S. You, S.H. Park, J. Alloys Compd. 690, 417 (2017)

[42] S.S. Park, B.S. You, D.J. Yoon, J. Mater. Process. Technol. 209, 5940 (2009)

[43] B. Jing, S. Yangshan, X. Feng, X. Shan, Q. Jing, T. Weijian, Scr. Mater. 55, 1163 (2006)

[44] S.H. Kim, J.U. Lee, Y.J. Kim, J.G. Jung, S.H. Park, J. Alloys Compd. 751, 1 (2018)

[45] J. She, F. Pan, J. Zhang, A. Tang, S. Luo, Z. Yu, K. Song, M. Rashad, J. Alloys Compd. 657, 893 (2016)
[46] S.W. Xu, M.Y. Zheng, S. Kamado, K. Wu, G.J. Wang, X.Y. Lv, Mater. Sci. Eng. A 528, 4055 (2011)

[47] H.F. Sun, C.J. Li, W.B. Fang, J. Mater. Process. Technol. 229, 633 (2016)

[48] H. Zengin, Y. Turen, Mater. Chem. Phys. 214, 421 (2018)

[49] G. Wang, G. Huang, X. Chen, Q. Deng, A. Tang, B. Jiang, F. Pan, Mater. Sci. Eng. A 705, 46 (2017)

[50] C.J. Wang, K.K. Deng, K.B. Nie, S.J. Shang, W. Liang, Mater. Sci. Eng. A 656, 102 (2016)

[51] W. Rong, Y. Zhang, Y.J. Wu, Y.L. Chen, M. Sun, J. Chen, L.M. Peng, Mater. Sci. Eng. A 740, 262 (2019)

[52] D. Zhao, X.H. Chen, J.L. Ye, T. Chen, Y. Dai, C.Q. Liu, Z. Luo, S.Q. Gao, J. Zhang, J.H. Yao, A. Atrens, A.T. Tang, F.S. Pan, J. Alloys Compd. 810, 151857 (2019)

[53] H. Zhang, H.Y. Wang, J.G. Wang, J. Rong, M. Zha, C. Wang, P.K. Ma, Q.C. Jiang, J. Alloys Compd. 780, 312 (2019)

[54] X.Y. Liu, L.W. Lu, K. Sheng, T. Zhou, Acta Metall. Sin. (Engl. Lett.) 32, 710 (2019)

[55] L. Zhang, K.K. Deng, K.B. Nie, F.J. Xu, K. Su, W. Liang, Mater. Sci. Eng. A 636, 279 (2015)

[56] C. Xu, T. Nakata, G.H. Fan, K. Yamanaka, G.Z. Tang, L. Geng, S. Kamado, Acta Metall. Sin. (Engl. Lett.) 32, 205 (2019)

[57] B. Li, B. Teng, D. Luo, Acta Metall. Sin. (Engl. Lett.) 31, 1009 (2018)

[58] R. Narayanasnmy, S. Sathiyanarayanan, R. Panalagusamy, J. Mater. Process. Techol. 102, 56 (2000)

[59] M.R. Barnett, Mater. Sci. Eng. A 464, 8 (2007)

[60] F.W. Jiao, L. Jin, J. Dong, F.H. Wang, Acta Metall. Sin. (Engl. Lett.) 32, 263 (2019)

[61] S.S.A. Shah, D. Wu, R.S. Chen, G.S. Song, Acta Metall. Sin. (Engl. Lett.) 33, 243 (2020)

[62] J. Kubásek, D. Dvorský, J. Veselý, P. Minárik, M. Zemková, D. Vojtěch, Acta Metall. Sin. (Engl. Lett.) 32, 321 (2019) 